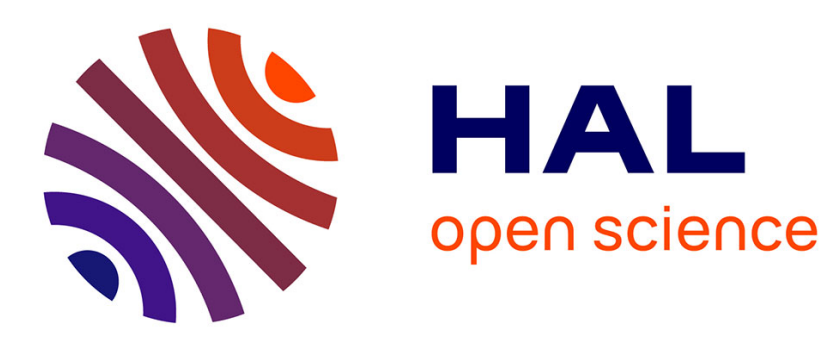

\title{
Neurobiological mechanisms of cannabinoid addiction
}

\author{
L. Fattore, P. Fadda, M.S. Spano, M. Pistis, W. Fratta
}

\section{To cite this version:}

L. Fattore, P. Fadda, M.S. Spano, M. Pistis, W. Fratta. Neurobiological mechanisms of cannabinoid addiction. Molecular and Cellular Endocrinology, 2008, 286 (1-2), 10.1016/j.mce.2008.02.006 . hal00531999

\section{HAL Id: hal-00531999 \\ https://hal.science/hal-00531999}

Submitted on 4 Nov 2010

HAL is a multi-disciplinary open access archive for the deposit and dissemination of scientific research documents, whether they are published or not. The documents may come from teaching and research institutions in France or abroad, or from public or private research centers.
L'archive ouverte pluridisciplinaire HAL, est destinée au dépôt et à la diffusion de documents scientifiques de niveau recherche, publiés ou non, émanant des établissements d'enseignement et de recherche français ou étrangers, des laboratoires publics ou privés. 


\section{Accepted Manuscript}

Title: Neurobiological mechanisms of cannabinoid addiction

Authors: L. Fattore, P. Fadda, M.S. Spano, M. Pistis, W. Fratta

PII:

S0303-7207(08)00067-1

DOI: doi:10.1016/j.mce.2008.02.006

Reference: $\quad$ MCE 6818

To appear in: $\quad$ Molecular and Cellular Endocrinology

Received date: $\quad 17-1-2008$

Revised date: $\quad 12-2-2008$

Accepted date: $\quad 12-2-2008$

Please cite this article as: Fattore, L., Fadda, P., Spano, M.S., Pistis, M., Fratta, W., Neurobiological mechanisms of cannabinoid addiction, Molecular and Cellular Endocrinology (2007), doi:10.1016/j.mce.2008.02.006

This is a PDF file of an unedited manuscript that has been accepted for publication. As a service to our customers we are providing this early version of the manuscript. The manuscript will undergo copyediting, typesetting, and review of the resulting proof before it is published in its final form. Please note that during the production process errors may be discovered which could affect the content, and all legal disclaimers that apply to the journal pertain. 


\title{
Neurobiological mechanisms of cannabinoid addiction
}

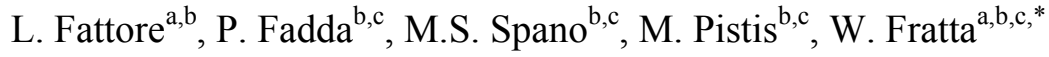 \\ ${ }^{a}$ Institute of Neuroscience CNR, National Research Council, Section of Cagliari, Italy \\ ${ }^{b}$ Centre of Excellence "Neurobiology of Dependence", Cagliari, Italy \\ ${ }^{c}$ Department of Neuroscience, University of Cagliari, Italy
}

Corresponding author:

Prof. Walter Fratta

Department of Neuroscience

Cittadella Universitaria di Monserrato

Monserrato-Cagliari

09042, Italy

Phone: +390706754313

Fax: +390706754312

E-mail:wfratta@unica.it 


\begin{abstract}
The endocannabinoid system is implicated in the regulation of a variety of physiological processes, among which conditioning, motivation, habit forming, memory, learning, and cognition play pivotal roles in drug reinforcement and reward. In this article we will give a synopsis of last developments in research on cannabinoid actions on brain reward circuits coming from behavioral, neurochemical and electrophysiological studies. Central cannabinoid-induced effects as measured by animal models of addiction, in vivo cerebral microdialysis, in vitro and in vivo electrophysiological recording techniques, will be reviewed. Brain sites that have been implicated in the mediation of addictive cannabinoid properties include primarily the ventral tegmental area, the nucleus accumbens, and the medial prefrontal cortex, although the amygdala, the substantia nigra, the globus pallidus, and the hippocampus have also been shown to be critical structures mediating motivational and reinforcing effects of cannabinoids. Putative neurobiological mechanisms underlying these effects will be delineated.
\end{abstract}

Keywords: Endocannabinoid system; CB1 receptor; dependence; reward; abuse; relapse 


\section{Introduction}

Marijuana smoking is the world's third most popular form of illicit drug use after alcohol drinking and tobacco smoking, with 160 million people (equivalent to $4 \%$ of the world's adult population) using cannabis each year (UNODC, 2006). Marijuana produces clear pleasurable and wellbeing feelings which peak at around 20 minutes and are virtually vanished 3 hours after its use (Ohlsson et al., 1980; Lindgren et al., 1981). Although cannabis dependence is moderate rather than severe, one in nine cannabis users satisfy the criteria for dependence, and the number of individuals requesting treatment for quitting cannabis use has been rising, particularly in Europe, Australia and United States (Murray et al., 2007).

Cannabis has been known as a medicine for several thousand years across many cultures. The discovery and cloning of the two subtypes of the G(i/o) protein-coupled cannabinoid receptors, the $\mathrm{CB} 1-\mathrm{R}$ and $\mathrm{CB} 2-\mathrm{R}$, as well as the isolation and characterization of different endogenous ligands, such as arachidonoylethanolamide (anandamide) and 2arachidonoylglycerol (2-AG), have opened new horizons in this field of research. Interest in the potential utility of cannabis-based medicines has been progressively increasing since observation of their beneficial effects in the treatment of chemotherapy-induced nausea and vomiting, appetite stimulation in patients with AIDS as well as in the relief from spasticity, neuropathic pain and sleep disturbances in patients with multiple sclerosis. Accordingly, a protective role of the eCB system has been proposed by biochemical, genetic and pharmacological studies using models of epilepsy, stroke, head trauma and neurodegenerative disorders, such as Huntington's, Parkinson's and Alzheimer's diseases (reviewed in Bisogno and Di Marzo, 2007; Micale et al., 2007). Moreover, promising evidence indicate that manipulation of the eCB system could be of help in treating several mood and mental 
disorders such as anxiety and depression (Viveros et al., 2005; Mangieri and Piomelli, 2007; Serra and Fratta, 2007).

Besides the homeostatic control of emotions, the regulation of motivated behavior is among the most important functions in which the eCB system is engaged, especially for its impact on human diseases such food and drug addiction (Di Marzo and Matias, 2005; Fattore et al., 2004, 2007a). For example, it has long been recognized that cannabinoid agonists stimulate food intake in animals, probably through enhancement of food palatability, while feeding-regulating hormones such as leptin can affect ECs synthesis in both the brain (Di Marzo et al., 2001) and periphery (Gomez et al., 2002). Further support of the role of the eCB system in regulating reinforcement processes activated by rewards of different nature stems from evidence that CB1-R blockade inhibits sucrose consumption (Arnone et al., 1997), while CB1-R activation increases food consumption elicited by electrical stimulation of the lateral hypothalamus, a brain area that participates in the regulation of food intake and incentive reward (Trojniar and Wise, 1991).

The distribution of cannabinoid receptors, both in the brain and in the periphery, along with the development of pharmacological tools to investigate their functions, has lead to a substantial increase in efforts to develop cannabinoids as therapeutic agents. However, a major impediment to the development of therapeutic cannabinoid medications is the occurrence of untoward cognitive and euphoric side effects of these drugs. Therefore, unraveling the mechanisms through which these actions occur is essential to developing rational approaches to medication development.

The neuroanatomical substrates of brain reward typically involve neural loci and mechanisms associated with the medial forebrain bundle, located largely in the ventral limbic midbrain. The mesolimbic dopamine (DA) system originating in the ventral tegmental area (VTA) is involved in neural processing contributing to drug addiction and it is widely accepted that this 
system processes rewarding stimuli, such as food, sex, money and addicting drugs, i.e. stimuli that are positively reinforcing and can elicit positive hedonic reactions (Wise, 2004). Axons of VTA DA neurons project to forebrain areas such as the nucleus accumbens (NAc) and the prefrontal cortex (PFC). CB1-Rs are abundantly expressed in these brain areas as well as in other structures related to motivation and reward, such as the substantia nigra (SN) pars reticulata, the olfactory tubercle, the hippocampus and the amygdala, which strongly contribute to the motivational and addictive properties of cannabinoids. Recently, a general role for the eCB system in the control of conditioned drug-seeking has been proposed (see De Vries and Schoffelmeer, 2005, and references therein), as well as in the reinstatement of druginduced reinstatement of extinguished drug-seeking behavior (see Fattore et al., 2007a,c, and references therein).

\section{Cannabinoids and drug addiction}

Numerous controlled laboratory studies indicated that marijuana serves as a positive reinforcer in humans (Mendelson and Mello, 1984; Foltin et al., 1989; Kelly et al., 1994b), and that delta9-tetrahydrocannabinol (THC) is an essential reinforcing component of marijuana (Kelly et al., 1994a; Haney et al., 1997). Content of THC, social context (i.e. work or social-access period) and presence of alternative reinforcers (i.e. snack food or money) may all significantly alter subjective-effect rating and marijuana intake in humans (Haney et al., 1997; Kelly et al. 1994a,b).

The abuse liability of cannabis derivatives has long been questioned, symptoms of abstinence in heavy marijuana users being quite rare to observe in humans (Hollister, 1986), probably because the slow clearance of cannabis from the body masks withdrawal symptoms. A first case of a withdrawal syndrome occurring in a woman after 21 days of marijuana smoking was reported by Mendelson et al. (1984), which described an abstinence syndrome beginning 10 
hours after cessation of marijuana smoking and lasting 96 hours. Behavioral and physiological abstinence phenomena after frequent administration of doses as high as $210 \mathrm{mg} /$ day of oral THC were also described (Haney et al., 1999). Over the past decade, demand for treatment for cannabis abuse has grown dramatically, and a large proportion of heavy users of hashish or ganja have difficult achieving and maintaining abstinence from the drug (McRae et al., 2003). Although pioneering studies has recently started to individuate possible useful targets for the treatment of cannabis abuse in humans (Solinas et al., 2007a; Haney et al., 2007), marijuana dependence appears difficult to treat, and its use leads to a risk of relapse as high as those found for other drugs of abuse (Stephens et al., 1994; Spear et al., 1999; Moore and Budney, 2003).

At preclinical level, it has been now definitely established that cannabinoids act on the brain in a way similar to other drugs of abuse (Gardner, 2002), producing clear subjective effects and leading to drug-seeking and drug-taking behavior (Martellotta et al., 1998; Fattore et al., 2001, 2007b; Justinova et al., 2003, 2005; Spano et al., 2004; Fadda et al., 2006; Deiana et al., 2007). However, the eCB system is not only the primary site of action for the motivational and reinforcing properties of cannabinoids, but it also exerts an overall modulatory effect on brain reward pathways, thus participating in the addictive properties of most drugs of abuse, such as alcohol (Mechoulam and Parker, 2003), nicotine (Viveros et al., 2006; Forget et al., 2006), cocaine (Arnold, 2005), opioids (Navarro et al., 2001; Fattore et al., 2004, 2005a, 2007d; Spano et al., 2007), methamphetamine (MDMA) (Parrott, 2006), and salvinorin (Braida et al., 2007a,b). Accordingly, mice not expressing the CB1-R do not selfadminister morphine (Ledent et al., 1999; Cossu et al., 2001), are less sensitive to the motivational and reinforcing effects of nicotine (Cohen et al., 2005) and alcohol (Thanos et al., 2005), and do not show ethanol withdrawal symptoms (Racz et al., 2003). 
Notably, high levels of CB1-Rs are present in the same brain regions, i.e. PFC, amygdala, NAc, and hippocampus, known to be involved in conditioned processes in laboratory animals and cue-elicited craving in human addicts (Everitt et al., 1999; Wang et al., 1999). In view of the evidence for an important role of CB1-Rs in the neuronal mechanisms underlying relapse to drug-seeking, blockade of the CB1-R is particularly effective in reducing drug- and cueinduced reinstatement of drug-seeking behavior in abstinent animals (Fattore et al., 2003, 2005b; Spano et al., 2004; De Vries et al., 2005; Filip et al., 2006; Xi et al., 2006; Economidou et al., 2007), as well as in preventing relapse in human cigarettes smokers (Le Foll and Goldberg, 2005).

As a result of a magnitude of behavioral, neurochemical and electrophysiological studies, the past years have witnessed a thoroughly remarkable advance in the elucidation of the neurobiological mechanisms underlying the reinforcing properties of cannabinoids and their actions on brain's reward system.

\subsection{Behavioural evidence}

Human addictive behavior can be successfully modeled in laboratory animals, with seemingly good face validity to the human situation. In this paragraph, evidence for the motivational, discriminative, conditioning and positive reinforcing effects of cannabinoids as revealed by animal models of addiction are reviewed.

It has been long recognized that laboratory animals, from rodents to monkeys, repeatedly self-administer through lever-pressing activity a mild electrical stimulation of specific brain sites, which has been found to be extremely pleasurable in humans as well. The first behavioral evidence that cannabinoids possess addictive potential was given by Gardner's group which demonstrated that low doses of THC were able to lower brain reward threshold, i.e. to enhance electrical brain stimulation reward (BSR) (Gardner et al., 1988; Gardner and 
Lowinson, 1991). In line with this, withdrawal from a single administration of THC is able to elevate the threshold for BSR (Gardner and Vorel, 1998). More recently, the synthetic CB1-R agonists WIN 55,212-2 and CP 55,940 have also shown to increase the threshold for BSR (Vlachou et al., 2005), although lack of effects of CP 55,940 was reported by one study using similar experimental conditions (Arnold et al., 2001). Subsequent observation by Gardner and colleagues of the existence of strain differences in such a behavior (Lepore et al., 1996) deserves special mention, as it represents the first demonstration of the key role played by this feature (i.e. animal strain) in rendering the addictive properties of cannabinoids manifest in behavioral protocols (see also below). Intriguingly, behavioural findings by Lepore et al. (1996) closely parallel the neurochemical ones reported by the same group, with THC producing robust enhancement of both BSR and accumbal DA level in drug-preferring Lewis rats, a moderate BSR and accumbal DA level enhancement in drug-neutral Sprague-Dawley rats, and no effect in drug-resistant Fisher 344 strain (Chen et al., 1991; Gardner et al., 2002).

Based on the assumption that the same components of a drug's action subserve discriminative stimulus (DS) effects in animals and subjective effects in humans, drug discrimination (DD) techniques are used to study abuse-related effects by establishing the interoceptive properties of a training drug as a cue for performing a specific operant response (Solinas et al., 2006). DD procedures typically involve training an animal to produce a particular response (lever-press or nose-poke) in a given drug state for a food reinforcer and to produce a different response in the placebo or drug-free state. The interoceptive cue state (produced by the drug) controls the behavior as a DS or cue that informs the animal to make the appropriate response in order to gain reinforcement. The choice of response that follows administration of an unknown test compound can provide valuable information about the similarity of that drug's interoceptive properties to those of the training drug. 
Studies employing this model have demonstrated that activation of CB1-Rs induces interoceptive effects in gerbils (Järbe et al., 1975), pigeons (Henriksson et al., 1975), rodents (Balster and Prescott, 1992), and monkeys (Wiley et al., 1995). Cannabinoid DS effects show high pharmacological specificity, as they are selectively blocked by CB1-R antagonists, although a partial overlap has been reported with diazepam (Mokler et al., 1986; Wiley and Martin, 1999), phencyclidine (Doty et al., 1994), and pentobarbital (Alici and Appel, 2004).

Cannabinoid behavioral effects have been extensively investigated also by conditioned place preference/aversion testing, a behavioral method believed capable of measuring the affective (positive, neutral or negative) properties of psychoactive drugs. The conditioned place preference (CPP) procedure is typically used to infer incentive motivational values of addictive drugs, and is based on the ability of a neutral stimulus to acquire incentive salience (Tzschentke 1998, 2007). Basically, animals experience two distinct neutral environments that during a conditioning period are spatially and temporally paired one with the training drug (drug-paired environment) and the other one with saline (non drug-paired environment). At the end of the conditioning, the animal is given the opportunity to choose to enter and explore both environments, and the time spent in each environment is measured. The animal's choice to stay longer in the drug-paired environment is assumed to be an expression of the positive reinforcing experience within that environment, and is therefore considered an index of the reinforcing value of the drug.

Depending on a number of experimental parameters (CB1-R agonist dose and/or potency, strain of animals) and procedural features (number of conditioning sessions, previous priming drug injections), cannabinoids have been reported to induce both conditioned place preference and aversion, or showed neither statistically significant preference or aversion. Interestingly, the EC transport inhibitor AM404 induces CPP in rats housed under enriched conditions, but not in rats kept in standard cages (Bortolato et al., 2006). Altogether, these studies have 
revealed a dose-dependent switch from reward to aversion, with low and high doses of cannabinoids inducing reward and aversion, respectively. An analogous phenomenon has been observed in human addicts, where low doses of THC or levonantradol are perceived as rewarding while higher doses as aversive (Noyes et al., 1975, Raft et al., 1977; Laszlo et al., 1981).

Drug self-administration (SA) paradigms are used for assessing drug-taking behavior, which can be investigated acutely in drug-naive animals, or chronically in animals trained to self-administer the drug. In these protocols, animals are allowed to self-administer a drug by pressing a specific lever or by inserting the nose into a specific hole provided with a photo beam. A correct lever-pressing or nose-poking response will result in the contingent presentation of reward, i.e. an intravenous infusion of the drug delivered by a computercontrolled syringe pump. At present, chronic SA procedures represent the most reliable animal model of addiction, which most closely resembles the human situation, allowing studying addictive behavior during all its phases, from initial acquisition of drug-taking behavior to extinction of such a behavior in absence of the drug, up to the reinstatement of drug-seeking following exposure to a drug or cue priming. Importantly, under controlled experimental conditions, laboratory animals do self-administer almost all drugs abused by humans, and in absence of physical dependence (Bozarth and Wise, 1984; Gardner, 1997, 2000).

Despite earlier reports of failure, more recent studies showed persistent and dose-dependent cannabinoid SA under different experimental conditions. Thus, intravenous SA of THC and AEA has been demonstrated in squirrel monkeys (Justinova et al., 2003, 2005), intravenous SA of WIN 55,212-2 has been reported in drug-naive mice (Martellotta et al., 1998; Fratta et al., 1999; Ledent et al., 1999; Fattore et al., 2002) and trained rats (Fattore et al., 2001, 2007b; Spano et al., 2004; Fadda et al., 2006; Deiana et al., 2007), while intracerebroventricular SA of CP 55,940 has been described in rats (Braida et al., 2001). Interestingly, cannabinoid SA is 
observed at very low doses, and is promptly blocked by pretreatment with CB1-R antagonists. Recently, a study from our laboratory have confirmed that, in line with the cannabinoidinduced enhancement of mesolimbic DA release and BSR threshold (Chen et al., 1991; Lepore et al., 1996), intravenous cannabinoid SA in rats also depends on the specific strain of animal used, such a behavior being clearly evident in Lister Hooded and Long Evans, but not Sprague-Dawley rats (Deiana et al., 2007). Moreover, cannabinoid intake by trained rats is significantly affected either by sex, females acquiring stable cannabinoid intake at higher rates and more rapidly than males, and by ovarian function, ovariectomised females being less sensible to cannabinoid rewarding effects than intact counterparts (Fattore et al., 2007b). Notably, the existence of sex differences in drug self-administration is an additional trait that cannabinoids share with other drugs of abuse (Fattore et al. 2008).

Consistent with these preclinical observations, the influence of non pharmacological variables (i.e. environmental setting, previous experience with the drug, personal expectation) on the subjective effects of marijuana in humans is known since early clinical studies (Hochman and Brill, 1971; Jones, 1971). When human subjects are given a choice between marijuana cigarettes with different THC concentrations, those with higher THC content are preferred over those containing lower THC concentrations (Chait and Zacny, 1992; Kelly et al., 1997), in support to the role of $\mathrm{THC}$ as the primary psychoactive ingredient of marijuana. Accordingly, experienced marijuana users would titrate their drug intake according to THC concentrations, in order to achieve an "optimal" subjective state (Cappell et al., 1973). Interestingly, marijuana self-administration in humans can be altered by the availability of alternative reinforcers such as money or snacks (Haney et al., 1997; Ward et al., 1997).

Finally, animal models of reinstatement are used to study relapse to drug-seeking and drug-taking behavior following a period even prolonged of drug abstinence. These protocols allowed investigation of this particular aspect of the addiction cycle which likely represents 
the core problem of the detoxification process, compulsive drug-seeking and intense drug craving often leading to the re-occurrence of drug use in abstinent patients. From an experimental point of view, animal models of reinstatement are an expansion of SA models, as animals are first trained to self-administer the drug, and then subjected to extinction of drugtaking behavior, usually obtained by substituting the rewarding self-administered drug with neutral physiological solution, during which responding does not result any more in the contingent presentation of the drug reward. That is, animals are tested under conditions of non-reinforcement until drug-taking behavior disappears and animals reach the defined criterion of non-drug-seeking. At this point, several stimuli can be used to trigger reinstatement of extinguished drug-seeking behavior, which have been shown to be essentially of the same nature of those effective in provoking craving and relapse in humans: $(i)$ reexposure to the previously experienced drug, (ii) drug-associated (conditioned) cues, or (iii) stressors, such as food deprivation or mild footshocks. A stimulus is said to reinstate drugseeking behavior if it elicits renewed responding despite the absence of any contingent reward. Intriguingly, cross-priming phenomena from one class of addictive drugs to another are commonly seen in this model and, once again, cannabinoids behave similarly to other drugs of abuse in this respect.

As assessed in reinstatement animal models, a role for the eCB system in regulating drugseeking behavior has been unequivocally demonstrated. Primings with CB1-R agonists are able to resume not only extinguished self-administration of cannabinoid (Spano et al., 2004), but also that of heroin (De Vries et al., 2003; Fattore et al., 2003), cocaine (De Vries et al., 2001), and alcohol-containing solutions (McGregor et al., 2005), while blockade of CB1-Rs is able to prevent drug- and/or cue-induced reinstatement of cannabinoid (Spano et al., 2004), heroin (Fattore et al., 2005b), nicotine (De Vries et al., 2005; Shoaib, 2007), alcohol (Cippitelli et al., 2005; Economidou et al., 2006), and MDMA (Anggadiredja et al., 2004). 
Relapse-preventing action of CB1-R antagonists were recently confirmed in clinical trials, at least for nicotine smoking, pointing to this class of compound as innovative approach in the treatment of drug addiction (Cahill and Ussher, 2007). Preclinical studies provided a solid framework for an important role of the eCB system in the neural mechanisms regulating body weight, probably by affecting the impact of food-associated stimuli, thus extending the clinical potential efficacy of CB1-R antagonists for the treatment of food addiction (Van Gaal et al., 2005).

\subsection{Neurochemical evidence}

Since its introduction in the 1980 's, in vivo microdialysis has been a popular and powerful research tool to determine modifications of various neurotransmitter extracellular concentrations in discrete brain area after acute or chronic drug treatment. Typically, a semipermeable membrane is stereotaxically implanted into a specific brain region in a freely moving animal. Endogenous substances that are low in concentration in the dialysis buffer and that possess a size small enough to diffuse through the membrane, will diffuse into it and will flow through another tube to be collected. Sensitive high-performance liquid chromatography (HPLC) procedures are usually employed to analyze the neurotransmitter of interest.

As mentioned before in this review, substances of abuse produce their addictive properties by primarily acting on the mesolimbic DA system that project from the VTA to the NAc (Koob, 1992; Wise, 2004). In vivo neurochemical studies in rats have shown that behaviorally relevant doses of the most commonly abused drugs produce an extended increase in extracellular DA levels in brain reward axon terminal loci and particularly in the NAc (Di Chiara and Imperato, 1988). For several years, this thought has been a subject of debate with regard to THC and cannabinoids, until Gardner's group showed that systemic administration of THC dose-dependently enhances DA extracellular concentrations in the striatum, PFC and 
NAc of rats (Ng Cheong Ton et al., 1988; Chen et al., 1990, 1991). The DA-releasing effect of CB1-R agonists in brain reward axon terminal loci has been demonstrated to be comparable to that of other drugs of abuse (i.e. cocaine, nicotine, opioids), and to satisfy the criteria to be considered a neuronal release, as it is dependent on action potentials (i.e. it is abolished by tetrodotoxin) and exocytosis (i.e. it is eliminated from the dialysates when calcium is omitted from the ringer) (Gardner, 2002).

However, discrepant results were also reported, as in the same years Castañeda and colleagues (1991) were unsuccessful to find any modifications in DA dialysate samples obtained from both striatum and NAc using the same experimental conditions with the only exception of the route of drug administration (gavauge vs intraperitoneal) and the strain of rats (Long Evans vs Sprague Dawley and Lewis).

Within the NAc, the two subregions shell and core, show different afferent and efferent connections and immunohistochemical characteristics (Groenewegen and Russchen, 1984; Voorn et al., 1989; Zahm and Brog, 1992). Neurochemical (Pontieri et al., 1995; Fadda et al., 2003) and behavioral (Cardinal et al., 2002; Kelley, 2004) findings support the notion of a major role played by the shell subregion of the NAc in motivated behavior as well as in conditioned and unconditioned rewarding drug effects (Everitt and Wolf, 2002; Ikemoto and Wise, 2004; Ito et al., 2004).

In line with other drugs of abuse, it was shown that cannabinoids preferentially stimulate DA release into the shell of the NAC, as both THC and WIN 55,212-2 induce a pronounced dosedependent effect in the shell, but only a weak response in the core after administration of high drug doses (Tanda et al., 1997). This DA-enhancing effect of cannabinoids is mediated not only by CB1-Rs, as it is specifically abolished by the CB1-R antagonist rimonabant (Tanda et al., 1997), but also by opioids receptors, as it is reversed by the unselective opioid receptor antagonist naloxone (Chen et al., 1990; Tanda et al., 1997). In addition, finding that intra-VTA 
injection of the $\mu$-opioid receptor antagonist naloxonazine blocks CB1-R agonist-enhanced DA extracellular levels in the shell of the NAc, further supports a functional interaction between opioids and cannabinoids in these mesencephalic structures (Tanda et al., 1997). On the other hand, morphine does not modify DA release in the NAc of mice lacking the CB1-R (knock-out mice) whereas it dose-dependently stimulates it in the corresponding wild-type mice (Mascia et al. 1999), demonstrating that CB1-Rs regulate mesolimbic dopaminergic transmission in brain areas known to be involved in the reinforcing effects of morphine. According to previous finding of a high degree of genetic variation in the behavioural effects of cannabinoids (Lepore et al., 1996; Deiana et al., 2007), neurochemical effects of cannabinoids also depend on animal strain studied (Chen et al., 1991). Indeed, since from the pioneering studies on cannabinoid administration effects on brain DA release, it has been demonstrated that low doses of THC elevate DA levels in the NAc of Lewis rats, did the same but to a lesser extend in Sprague Dawley rats, and induced not changes in Fisher strain (Chen et al., 1991; Gardner, 2002).

More recently, it has been reported that AEA also possesses the ability to produce a fast and significant elevation in extracellular DA levels in the shell of the NAc when injected intravenously (Solinas et al., 2006, 2007b). In addition, inhibition of the fatty acid amide (FAAH) by URB597, but not inhibition of AEA transport by AM404 or UCM707, considerably potentiates both the duration and the magnitude of the AEA-induced DA rise, suggesting brain specificity for FAAH versus transport/FAAH inactivation of AEA (Solinas et al., 2006, 2007b).

Extracellular DA in the rat NAc significantly increases in response to either passive administration, i.e. given by the experimenter, or active injection, i.e. self-administered by the subject itself, of the most commonly abused drugs (Di Chiara and Imperato, 1988; Pettit and Justice, 1989). 
As in the abovementioned studies, cannabinoids effect on DA extracellular levels was long investigated exclusively in animals receiving the drug passively. Few years ago, by combining intravenous self-administration procedure with in vivo microdialysis technique we measured fluctuations of DA levels in the NAc of rats during voluntary WIN 55,212-2 intake (Fadda et al., 2006). In this study we demonstrated that self-administered doses of intravenous WIN 55,212-2 increase DA release to a similar extent in the NAc shell of Lister Hooded and Long Evans rats, with a significant relationship between extracellular DA levels and bar-pressing rates, thus providing a reasonable neurochemical basis for the reinforcing effects of cannabinoid (Fadda et al., 2006).

Generally, neurochemical studies investigating the role of CB1-R agonist administration in drug reward and addictive behavior are focused on DA release in the NAc, in view of a putative increased electrical activity of DA neurons in the VTA. However, the enhanced DA release in the NAc could be not the result of a direct effect on DA cells, but rather the result of an indirect action on glutamatercic and GABAergic terminals impinging on DA neurons (Marinelli et al., 2007; Wenger et al., 2003). Less numerous but as much interesting are studies reporting effects of cannabinoid administration on GABA, glutamate, $\mathrm{NE}$ and Ach release in several brain area, such as the PFC, the striatum, the hippocampus, that are all related to emotional and/or cognitive functions (Degroot and Nomikos, 2007).

\subsection{Electrophysiological evidence}

Electrophysiological studies targeted at the understanding the neural mechanisms underlying addiction to cannabinoids and the involvement of the eCB system in drug abuse and reward have been focused mainly on mesolimbic DA neurons, the NAc, and associated limbic structures. 
The eCB system has emerged as an important modulator of the DA neurons. Exogenous cannabinoid agonists stimulate the activity of mesencephalic DA neurons (French et al., 1997; Gessa et al., 1998). Both THC and synthetic CB1-R agonists dose-dependently enhance firing rate and bursting activity of DA neurons in the VTA, whereas their actions on DA neurons in the pars compacta of the substantia nigra $(\mathrm{SNc})$ are less pronounced. Enhanced electrical activity translates into an increase in DA release in terminal regions, such as the NAc (Cheer et al., 2004; Fadda et al., 2006; Tanda et al., 1997; Pistis et al., 2002b) and the PFC (Chen et al., 1990, Chen et al., 1993; Pistis et al., 2002a). Under this aspect, cannabinoids display effects largely similar to those of other drugs of abuse belonging to different classes. Indeed, drugs abused by humans enhance DA transmission by diverse mechanisms, i.e. by enhancing firing rate of DA neurons and DA release in the NAc, such as alcohol, nicotine, GHB, opioids and cannabinoids (Di Chiara and Imperato, 1988; Gessa et al., 1985; Matthews and German, 1984; Mereu et al., 1987; Pistis et al., 2005), or by directly acting at dopaminergic terminals, such as cocaine and amphetamine (Di Chiara and Imperato, 1988; Einhorn et al., 1988). On the other hand, during withdrawal from chronic cannabinoid treatment, DA neurons display a reduced baseline activity (Diana et al., 1998), which is an additional trait in common with other drugs of abuse, such as alcohol and morphine (Diana et al., 1993, 1995).

Cannabinoid agonists most probably do not directly activate DA cells, since CB1-R or mRNA levels in the VTA and in the SNc are very low or undetectable (Herkenham et al., 1991; Matsuda et al., 1993). In fact, neurons from different areas projecting to VTA or SNc possess relatively large amounts of $\mathrm{CB} 1$ receptor mRNA, namely the glutamatergic neurons in the PFC and in the subthalamic nucleus (STN), or the GABAergic neurons in the striatal complex as well as in the pars reticulata of the substantia nigra (SNr) (Marsicano and Lutz, 1999; Matsuda et al., 1993). Thus, it is presumed that low levels of CB1-Rs are located on glutamatergic and GABAergic terminals impinging on DA neurons (Marinelli et al., 2007; 
Wenger et al., 2003), where they can finely regulate the release of inhibitory and excitatory neurotransmitters and DA neuron activity.

Consistently, in vitro electrophysiological experiments have provided evidence that CB1-R agonists depress inhibitory and excitatory post-synaptic currents recorded from DA neurons (Marinelli et al., 2007; Melis et al., 2004b; Szabo et al., 2002). The presence of CB1-Rs strongly suggested a physiological role of the eCB system in modulating synaptic functions. Hence, patch-clamp studies demonstrated that DA neurons release ECs as retrograde messengers in a $\mathrm{Ca}^{2+}$-dependent manner (Melis et al., 2004a; Riegel and Lupica, 2004) during depolarization of the cell (Melis et al., 2004b), stimulation of excitatory afferents (Melis et al., 2004a), induction of burst firing in vivo (Melis et al., 2004a) and in vitro (Riegel and Lupica, 2004). Under these circumstances, released ECs transiently modulate presynaptically afferent activity and suppress incoming inputs, thus inducing neuroprotective effects (Melis et al., 2006; Melis and Pistis, 2007), or forms of synaptic depression such as depolarization-induced suppression of excitation (DSE) and depolarization-induced suppression of inhibition (DSI) (Melis et al., 2004b; Riegel and Lupica, 2004; Yanovsky et al., 2003). Among different endocannabinoids, 2-AG, and not AEA, is the most likely messenger in synaptic modulation in DA neurons (Melis et al., 2004a, 2006). The functional consequences of eCB signalling in DA neurons are not completely understood yet. One hypothesis is that the eCB system regulates firing and pattern activity of DA neurons.

These cells fire in vivo in two main different patterns of activity: regular pace-maker-like activity and burst firing (Grace and Bunney, 1983), this latter being more efficacious than the former in releasing DA in the NAc (Gonon, 1988). Thus, the functional efficacy of DA neurons crucially depends on firing pattern (bursting vs regular) rather than on the simple average firing frequency. In turn, firing rate and pattern of DA neurons depend on the activity of excitatory and inhibitory inputs (Marinelli et al., 2006), so that a feedback control of these 
inputs (such as that exerted by ECs) is crucial for normal functioning of DA neurons. Switching from regular to burst firing can be triggered by behavioural stimuli such as reward prediction error (Schultz, 1998, 2002, 2006; Schultz and Dickinson, 2000). Thus, the finding that ECs may be released during burst of DA neurons, similar to those caused by behaviorally salient events, appears particularly remarkable, since these molecules may have an important role in modulating signal-to-noise ratio of DA neuron activity, especially during emotional processing and sensory perception (Laviolette and Grace, 2006). Indeed, exogenous cannabinoids may profoundly affect emotional and sensory perception as well as motivation and reward by co-opting these finely regulated physiological mechanisms.

\section{Circuit mechanisms contributing to cannabinoid addiction}

On the basis of more than two decades of behavioural, neurochemical and electrophysiological studies, it is clear that cannabinoids have multiple potential sites of action, both within and outside the VTA, and act through different mechanisms within the multifaceted brain's reward circuitry.

Finding of colocalization of immunoreactivity for the CB1-R and for the DA synthesizing enzyme tyrosine hydroxylase, commonly used as a cellular marker for the presence of DA neurons (Wenger et al., 2003), led to the hypothesis of a CB1-R mediated direct action of cannabinoid agonists on VTA DA neurons. However, it is recognized now that VTA DA neurons are unlikely to express CB1-Rs (Matsuda et al., 1993; Julian et al., 2003), thus leading researchers to put forward new indirect mechanisms of action for cannabinoids in the brain.

CB1-R activation may in fact increase local VTA DA neuronal activity by altering the balance between the GABA inhibitory inputs on VTA DA neurons (through activation of CB1-Rs present on axon terminals of GABAergic VTA neurons) and the glutamatergic synaptic transmission from PFC neurons projecting to the VTA and NAc. In addition to its 
action on mechanisms common to other drugs of abuse (Johnson and North, 1992), the eCB system may participate in the addictive properties of cannabinoids and other addictive drugs by permitting the effects of these drugs on mesolimbic DA transmission. Indeed, ECs are released in the VTA following an increment in the firing rates of DA neurons and stimulation of excitatory afferents (Melis et al., 2004b; Lupica and Riegel 2005), which would explain the role of the eCB system in the modulation of the primary rewarding effects of cannabinoids, opioids, nicotine and alcohol, but not psychostimulants (i.e. cocaine) which instead increase DA levels in the NAc by directly acting on DA axon terminals.

Parallel DA-independent mechanisms may also be engaged by CB1-Rs activation, involving for example CB1-Rs present in the $\mathrm{PFC}$, a brain area integrating sensory information, emotional processing and hedonic experience, which would explain the involvement of the eCB system in the motivation to seek the drug. A complementary different mechanism would give explanation for the general role of the eCB system in the reinstatement of drug-seeking behavior, probably by modulating synaptic plasticity in those brain areas (i.e. NAc, PFC, amygdala, hippocampus) underlying reward-related memories, thus consolidating the reward-driven behavior required to establish addictive processes.

\section{Concluding remarks and future perspective}

Identifying the nature of cannabinoid action in the brain is crucial in the optimization of potential benefit of cannabinoid-based medications as well as in developing treatment strategies for individuals attempting to quit marijuana smoking. The presence of the eCB system in reward circuits and its role in the control of motivational and emotional homeostasis suggest that drugs able to modulate cannabinoid brain signaling may serve as therapeutic tools in drug addiction. 
The last decade of research on cannabinoids has led to the discovery of multiple eCB molecules in the brain, the individuation of their synthesis and degradation mechanisms, and their action as retrograde messengers. However, regardless of the enormous conceptual advances made in recent years, we still have to precisely map the brain sites that make cannabinoid drugs rewarding and able to induce dependence. The intimate brain mechanisms and substrates through which the eCB system regulates reward and addiction processes and interacts with other brain neurotransmitters are still to be identified. 


\section{References}

Alici, T., Appel, J.B., 2004. Increasing the selectivity of the discriminative stimulus effects of delta 9-tetrahydrocannabinol: complete substitution with methanandamide. Pharmacol. Biochem. Behav. 79, 431-437.

Anggadiredja, K., Nakamichi, M., Hiranita, T., Tanaka, H., Shoyama, Y., Watanabe, S., Yamamoto, T., 2004. Endocannabinoid system modulates relapse to methamphetamine seeking: possible mediation by the arachidonic acid cascade. Neuropsychopharmacology 29, 1470-1478.

Arnold, J.C., Hunt, G.E., McGregor, I.S., 2001. Effects of the cannabinoid receptor agonist CP 55,940 and the cannabinoid receptor antagonist SR 141716 on intracranial self-stimulation in Lewis rats. Life Sci. 70, 97-108.

Arnold, J.C., 2005. The role of endocannabinoid transmission in cocaine addiction. Pharmacol. Biochem. Behav. 81, 396-406.

Arnone, M., Maruani, J., Chaperon, F., Thiébot, M.H., Poncelet, M., Soubrié, P., Le Fur, G., 1997. Selective inhibition of sucrose and ethanol intake by SR 141716, an antagonist of central cannabinoid (CB1) receptors. Psychopharmacology 132, 104-106.

Balster, R.L., Prescott, W.R., 1992. Delta 9-tetrahydrocannabinol discrimination in rats as a model for cannabis intoxication. Neurosci. Biobehav. Rev. 16, 55-62.

Bisogno, T., Di Marzo, V., 2007. Short- and long-term plasticity of the endocannabinoid system in neuropsychiatric and neurological disorders. Pharmacol. Res. 56, 428-442.

Bortolato, M., Campolongo, P., Manieri, R.A., Scattoni, M.L., Frau, R., Trezza, V., La Rana, G., Russo, R., Calignano, A., Gessa, G.L., Cuomo, V., Piomelli, D., 2006. Anxiolytic-like properties of the anandamide transport inhibitor AM404. Neuropsychopharmacology 31, 2652-2659.

Bozarth, M.A., Wise, R.A., 1984. Anatomically distinct opiate receptor fields mediate reward and physical dependence. Science 224, 516-517.

Braida, D., Pozzi, M., Parolaro, D., Sala, M., 2001. Intracerebral self-administration of the cannabinoid receptor agonist CP 55,940 in the rat: interaction with the opioid system. Eur. J. Pharmacol. 413; 227-234. 
Braida, D., Limonta, V., Pegorini, S., Zani, A., Guerini-Rocco, C., Gori, E., Sala, M., 2007a. Hallucinatory and rewarding effect of salvinorin A in zebrafish: kappa-opioid and CB1cannabinoid receptor involvement. Psychopharmacology 190, 441-448.

Braida, D., Lmonta, V., Capurro, V., Fadda, P., Rubino, T., Mascia, P., Zani, A., Gori, E., Fratta, W., Parolaro, D., Sala, M., 2007b. Involvement of kappa-Opioid and Endocannabinoid System on Salvinorin A-Induced Reward. Biol. Psychiatry 63, 286-292.

Cahill, K., Ussher, M., 2007. Cannabinoid type 1 receptor antagonists (rimonabant) for smoking cessation. Cochrane Database Syst Rev. 17 CD005353.

Cappell, H., Kuchar, E., Webster, C.D., 1973. Some correlates of marihuana self-administration in man: a study of titration of intake as a function of drug potency. Psychopharmacologia 29, $177-184$.

Cardinal, R.N., Parkinson, J.A., Hall, J., Everitt, B.J., 2002. Emotion and motivation: the role of the amygdala, ventral striatum, and prefrontal cortex. Neurosci. Biobehav. Rev. 26, 321-352.

Castañeda, E., Moss, D.E., Oddie, S.D., Whishaw, I.Q., 1991. THC does not affect striatal dopamine release: microdialysis in freely moving rats. Pharmacol. Biochem. Behav. 40, 587591.

Chait, L.D., Zacny, J.P., 1992. Reinforcing and subjective effects of oral delta 9-THC and smoked marijuana in humans. Psychopharmacology 107, 255-262.

Cheer, J.F., Wassum, K.M., Heien, M.L., Phillips, P.E., Wightman, R.M., 2004. Cannabinoids enhance subsecond dopamine release in the nucleus accumbens of awake rats. J. Neurosci. 24, 4393-4400.

Chen, J., Paredes, W., Lowinson, J.H., Gardner, E.L., 1990. Delta 9-tetrahydrocannabinol enhances presynaptic dopamine efflux in medial prefrontal cortex. Eur. J. Pharmacol. 190, 259-262.

Chen, J.P., Paredes, W., Lowinson, J.H., Gardner, E.L., 1991. Strain-specific facilitation of dopamine efflux by delta 9-tetrahydrocannabinol in the nucleus accumbens of rat: an in vivo microdialysis study. Neurosci. Lett. 129, 136-180.

Chen, J., Marmur, R., Pulles, A., Paredes, W., Gardner, E.L., 1993. Ventral tegmental microinjection of delta 9-tetrahydrocannabinol enhances ventral tegmental somatodendritic dopamine levels but not forebrain dopamine levels: evidence for local neural action by marijuana's psychoactive ingredient. Brain Res. 621, 65-70. 
Cippitelli, A., Bilbao, A., Hansson, A.C., del Arco, I., Sommer, W., Heilig, M., Massi, M., Bermúdez-Silva, F.J., Navarro, M., Ciccocioppo, R., de Fonseca, F.R., 2005. Cannabinoid CB1 receptor antagonism reduces conditioned reinstatement of ethanol-seeking behavior in rats. Eur. J. Neurosci. 21; 2243-2251.

Cohen, C., Kodas, E., Griebel, G., 2005. CB1 receptor antagonists for the treatment of nicotine addiction. Pharmacol. Biochem. Behav. 81, 387-395.

Cossu, G., Ledent, C., Fattore, L., Imperato, A., Böhme, G.A., Parmentier, M., Fratta, W., 2001. Cannabinoid CB1 receptor knockout mice fail to self-administer morphine but not other drugs of abuse. Behav. Brain Res. 118, 61-65.

Degroot, A., Nomikos, G.G., 2007. In vivo neurochemical effects induced by changes in endocannabinoid neurotransmission. Curr. Opin. Pharmacol. 7, 62-68.

Deiana, S., Fattore, L., Spano, M.S., Cossu, G., Porcu, E., Fadda, P., Fratta, W., 2007. Strain and schedule-dependent differences in the acquisition, maintenance and extinction of intravenous cannabinoid self-administration in rats. Neuropharmacology 52, 646-654.

De Vries, T.J., Schoffelmeer, A.N., 2005. Cannabinoid CB1 receptors control conditioned drug seeking. Trends Pharmacol. Sci. 26, 420-426.

De Vries, T.J., Shaham, Y., Homberg, J.R., Crombag, H., Schuurman, K., Dieben, J., Vanderschuren, L.J., Schoffelmeer, A.N., 2001. A cannabinoid mechanism in relapse to cocaine seeking. Nat. Med. 7, 1151-1154.

De Vries, T.J., Homberg, J.R., Binnekade, R., Raasø, H., Schoffelmeer, A.N., 2003. Cannabinoid modulation of the reinforcing and motivational properties of heroin and heroin-associated cues in rats. Psychopharmacology 168, 164-169.

De Vries, T.J., de Vries, W., Janssen, M.C., Schoffelmeer, A.N., 2005. Suppression of conditioned nicotine and sucrose seeking by the cannabinoid-1 receptor antagonist SR141716A. Behav. Brain Res. 161, 164-168.

Di Chiara, G., Imperato, A., 1988. Drugs abused by humans preferentially increase synaptic dopamine concentrations in the mesolimbic system of freely moving rats. Proc. Natl. Acad. Sci. U.S.A. $85,5274-5278$.

Di Marzo, V., Berrendero, F., Bisogno, T., González, S., Cavaliere, P., Romero, J., Cebeira, M., Ramos, J.A., Fernández-Ruiz, J.J., 2000. Enhancement of anandamide formation in the limbic 
forebrain and reduction of endocannabinoid contents in the striatum of delta9tetrahydrocannabinol-tolerant rats. J. Neurochem. 74, 1627-1635.

Di Marzo, V., Goparaju, S.K., Wang, L., Liu, J., Bátkai, S., Járai, Z., Fezza, F., Miura, G.I., Palmiter, R.D., Sugiura, T., Kunos, G., 2001. Leptin-regulated endocannabinoids are involved in maintaining food intake. Nature 410, 822-825.

Di Marzo, V., Matias, I., 2005. Endocannabinoid control of food intake and energy balance. Nat. Neurosci. 8, 585-589.

Diana, M., Pistis, M., Carboni, S., Gessa, G.L., Rossetti, Z.L., 1993. Profound decrement of mesolimbic dopaminergic neuronal activity during ethanol withdrawal syndrome in rats: electrophysiological and biochemical evidence. Proc. Natl. Acad. Sci. U.S.A. 90, 7966-7969.

Diana, M., Pistis, M., Muntoni, A., Gessa, G., 1995. Profound decrease of mesolimbic dopaminergic neuronal activity in morphine withdrawn rats. J. Pharmacol. Exp. Ther. 272, 781-785.

Diana, M., Melis, M., Muntoni, A.L., Gessa, G.L., 1998. Mesolimbic dopaminergic decline after cannabinoid withdrawal. Proc. Natl. Acad. Sci. U.S.A. 95, 10269-10273.

Doty, P., Dykstra, L.A., Picker, M.J., 1994. Discriminative stimulus effects of phencyclidine: pharmacologically specific interactions with delta9- and delta8-tetrahydrocannabinol. Drug Alcohol Depend. 35, 151-158.

Economidou, D., Mattioli, L., Cifani, C., Perfumi, M., Massi, M., Cuomo, V., Trabace, L., Ciccocioppo, R., 2006. Effect of the cannabinoid CB1 receptor antagonist SR-141716A on ethanol self-administration and ethanol-seeking behaviour in rats. Psychopharmacology 183, 394-403.

Economidou, D., Mattioli, L., Ubaldi, M., Lourdusamy, A., Soverchia, L., Hardiman, G., Campolongo, P., Cuomo, V., Ciccocioppo, R., 2007. Role of cannabinoidergic mechanisms in ethanol self-administration and ethanol seeking in rat adult offspring following perinatal exposure to Delta9-tetrahydrocannabinol. Toxicol. Appl. Pharmacol. 223, 73-85.

Einhorn, L.C., Johansen, P.A., White, F.J., 1988. Electrophysiological effects of cocaine in the mesoaccumbens dopamine system: studies in the ventral tegmental area. J. Neurosci. 8, 100112. 
Everitt, B.J., Parkinson, J.A., Olmstead, M.C., Arroyo, M., Robledo, P., Robbins, T.W., 1999. Associative processes in addiction and reward. The role of amygdala-ventral striatal subsystems. Ann. N.Y. Acad. Sci. 877, 412-438.

Everitt, B.J., Wolf, M.E., 2002. Psychomotor stimulant addiction: a neural systems perspective. J. Neurosci. 22, 3312-3320.

Fadda, P., Scherma, M., Fresu, A., Collu, M., Fratta, W., 2003. Baclofen antagonizes nicotine-, cocaine-, and morphine-induced dopamine release in the nucleus accumbens of rat. Synapse $50,1-6$.

Fadda, P., Scherma, M., Spano, M.S., Salis, P., Melis, V., Fattore, L., Fratta, W., 2006. Cannabinoid self-administration increases dopamine release in the nucleus accumbens. Neuroreport 17, 1629-1632.

Fattore, L., Cossu, G., Martellotta, C.M., Fratta, W., 2001. Intravenous self-administration of the cannabinoid CB1 receptor agonist WIN 55,212-2 in rats. Psychopharmacology 156, 410-416.

Fattore, L., Cossu, G., Fratta, W., 2002. Functional interaction between cannabinoids and opioids in animal models of drug addiction. Proceedings of the "Frontiers in Addiction Research" NIDA symposium satellite at the SfN Meeting, 1-2 Nov 2002, Orlando (USA).

Fattore, L., Spano, M.S., Cossu, G., Deiana, S., Fratta, W., 2003. Cannabinoid mechanism in reinstatement of heroin-seeking after a long period of abstinence in rats. Eur. J. Neurosci. 17, $1723-1726$.

Fattore, L., Cossu, G., Spano, M.S., Deiana, S., Fadda, P., Scherma, M., Fratta, W., 2004. Cannabinoids and reward: interactions with the opioid system. Crit. Rev. Neurobiol. 16, 147158.

Fattore, L., Deiana, S., Spano, M.S., Cossu, G., Fadda, P., Scherma, M., Fratta, W., $2005 a$. Endocannabinoid system and opioid addiction: behavioural aspects. Pharmacol. Biochem. Behav. 81, 343-359.

Fattore, L., Spano, M.S., Cossu, G., Deiana, S., Fadda, P., Fratta, W., 2005b. Cannabinoid CB(1) antagonist SR 141716A attenuates reinstatement of heroin self-administration in heroinabstinent rats. Neuropharmacology 8, 1097-1104.

Fattore, L., Fadda, P., Fratta, W., 2007a. Endocannabinoid regulation of relapse mechanisms. Pharmacol. Res. 56, 418-427. 
Fattore, L., Spano, M.S., Altea, S., Angius, F., Fadda, P., Fratta, W., 2007b. Cannabinoid selfadministration in rats: sex differences and the influence of ovarian function. Br. J. Pharmacol. $152,795-804$.

Fattore, L., Spano, M.S., Deiana, S., Melis, V., Cossu, G., Fadda, P., Fratta, W., 2007c. An endocannabinoid mechanism in relapse to drug seeking: a review of animal studies and clinical perspectives. Brain Res. Rev. 53, 1-16.

Fattore, L., Viganò, D., Fadda, P., Rubino, T., Fratta, W., Parolaro, D., 2007d. Bidirectional regulation of mu-opioid and $\mathrm{CB1}$-cannabinoid receptor in rats self-administering heroin or WIN 55,212-2. Eur. J. Neurosci. 25, 2191-2200.

Fattore, L., Altea, S., Fratta, W., 2008. Sex differences in drug addiction: a review of animal and human studies. Women's Health, in press.

Filip, M., Gołda, A., Zaniewska, M., McCreary, A.C., Nowak, E., Kolasiewicz, W., Przegaliński, E., 2006. Involvement of cannabinoid CB1 receptors in drug addiction: effects of rimonabant on behavioral responses induced by cocaine. Pharmacol. Rep. 58, 806-819.

Foltin, R.W., Fischman, M.W., Brady, J.V., Capriotti, R.M., Emurian, C.S., 1989. The regularity of smoked marijuana self-administration. Pharmacol. Biochem. Behav. 32, 483-486.

Forget, B., Barthélémy, S., Saurini, F., Hamon, M., Thiébot, M.H., 2006. Differential involvement of the endocannabinoid system in short- and long-term expression of incentive learning supported by nicotine in rats. Psychopharmacology 189, 59-69.

Fratta, W., Cossu, G., Martellotta, M.C., Fattore, L., 1999. A common neurobiological mechanism regulates cannabinoid and opioid rewarding effects in mice. Neurosci. Lett., 52, S10-S11.

French, E.D., Dillon, K., Wu, X., 1997. Cannabinoids excite dopamine neurons in the ventral tegmentum and substantia nigra. Neuroreport 8, 649-652.

Gardner, E.L., 1997. Brain reward mechanisms. In: Lowinson, J.H., Ruiz, P., Millman, R.B., Langrod, J.G. (eds.), Substance Abuse: A Comprehensive Textbook. Williams \& Wilkins, Baltimore, pp. 51-85.

Gardner, E.L., 2000. What we have learned about addiction from animal models of drug selfadministration. Am. J. Addict. 9, 285-313.

Gardner, E.L., 2002. Addictive potential of cannabinoids: the underlying neurobiology. Chem. Phys. Lipids 121, 267-290. 
Gardner, E.L., Lowinson, J.H., 1991. Marijuana's interaction with brain reward systems: update 1991. Pharmacol. Biochem. Behav. 40, 571-580.

Gardner, E.L., Vorel, S.R., 1998. Cannabinoid transmission and reward-related events. Neurobiol. Dis. 5, 502-533.

Gardner, E.L., Paredes, W., Smith, D., Donner, A., Milling, C., Cohen, D., Morrison, D., 1988. Facilitation of brain stimulation reward by delta 9-tetrahydrocannabinol. Psychopharmacology $96,142-144$.

Gessa, G.L., Muntoni, F., Collu, M., Vargiu, L., Mereu, G., 1985. Low doses of ethanol activate dopaminergic neurons in the ventral tegmental area. Brain Res. 348, 201-203.

Gessa, G.L., Melis, M., Muntoni, A.L., Diana, M., 1998. Cannabinoids activate mesolimbic dopamine neurons by an action on cannabinoid CB1 receptors. Eur. J. Pharmacol. 341, 39-44.

Glass, M., Dragunow, M., Faull, R.L., 1997. Cannabinoid receptors in the human brain: a detailed anatomical and quantitative autoradiographic study in the fetal, neonatal and adult human brain. Neuroscience 77, 299-318.

Gómez, R., Navarro, M., Ferrer, B., Trigo, J.M., Bilbao, A., Del Arco, I., Cippitelli, A., Nava, F., Piomelli, D., Rodríguez de Fonseca, F., 2002. A peripheral mechanism for CB1 cannabinoid receptor-dependent modulation of feeding. J. Neurosci. 22, 9612-9617.

Gonon, F.G., 1988. Nonlinear relationship between impulse flow and dopamine released by rat midbrain dopaminergic neurons as studied by in vivo electrochemistry. Neuroscience 24, 1928.

Grace, A.A., Bunney, B.S., 1983. Intracellular and extracellular electrophysiology of nigral dopaminergic neurons--1. Identification and characterization. Neuroscience 10, 301-315.

Groenewegen, H.J., Russchen, F.T., 1984. Organization of the efferent projections of the nucleus accumbens to pallidal, hypothalamic, and mesencephalic structures: a tracing and immunohistochemical study in the cat. J. Comp. Neurol. 223, 347-367.

Haney, M., Comer, S.D., Ward, A.S., Foltin, R.W., Fischman, M.W., 1997. Factors influencing marijuana self-administration by humans. Behav. Pharmacol. 8, 101-112.

Haney, M., Ward, A.S., Comer, S.D., Foltin, R.W., Fischman, M.W., 1999. Abstinence symptoms following oral THC administration to humans. Psychopharmacology 141, 385-394. 
Haney, M. 2007. Opioid antagonism of cannabinoid effects: differences between marijuana smokers and nonmarijuana smokers. Neuropsychopharmacology 32,1391-1403.

Henriksson, B.G., Johansson, J.O., Järbe, T.U., 1975. Delta 9-tetrahydrocannabinol produced discrimination in pigeons. Pharmacol. Biochem. Behav. 3, 771-774.

Herkenham, M., Lynn, A.B., Johnson, M.R., Melvin, L.S., de Costa, B.R., Rice, K.C., 1991. Characterization and localization of cannabinoid receptors in rat brain: a quantitative in vitro autoradiographic study. J. Neurosci. 11, 563-583.

Hochman, J.S., Brill, N.Q., 1971. Marijuana intoxication: pharmacological and psychological factors. Dis. Nerv. Syst. 32; 676-679.

Hollister, L.E., 1986. Health aspects of cannabis. Pharmacol. Rev. 38, 1-20.

Hutcheson, D.M., Tzavara, E.T., Smadja, C., Valjent, E., Roques, B.P., Hanoune, J., Maldonado, R., 1998. Behavioural and biochemical evidence for signs of abstinence in mice chronically treated with delta-9-tetrahydrocannabinol. Br. J. Pharmacol. 125, 1567-1577.

Ikemoto, S., Wise, R.A., 2004. Mapping of chemical trigger zones for reward. Neuropharmacology 47, 190-201.

Ito, R., Robbins, T.W., Everitt, B.J., 2004. Differential control over cocaine-seeking behavior by nucleus accumbens core and shell. Nat. Neurosci. 7, 389-397.

Järbe, T.U., Johansson, J.O., Henriksson, B.G., 1975. Delta9-tetrahydrocannabinol and pentobarbital as discriminative cues in the Mongolian Gerbil (Meriones unguiculatus). Pharmacol. Biochem. Behav. 3, 403-410.

Johnson, S.W., North, R.A., 1992. Opioids excite dopamine neurons by hyperpolarization of local interneurons. J. Neurosci. 12, 483-488.

Jones, R.T., 1971. Marihuana-induced "high": influence of expectation, setting and previous drug experience. Pharmacol. Rev. 23, 359-369.

Julian, M.D., Martin, A.B., Cuellar, B., Rodriguez De Fonseca, F., Navarro, M., Moratalla, R., Garcia-Segura, L.M., 2003. Neuroanatomical relationship between type 1 cannabinoid receptors and dopaminergic systems in the rat basal ganglia. Neuroscience 119, 309-318.

Justinova, Z., Tanda, G., Redhi, G.H., Goldberg, S.R., 2003. Self-administration of delta9tetrahydrocannabinol (THC) by drug naive squirrel monkeys. Psychopharmacology 169, 135140. 
Justinova, Z., Solinas, M., Tanda, G., Redhi, G.H., Goldberg, S.R., 2005. The endogenous cannabinoid anandamide and its synthetic analog $\mathrm{R}(+)$-methanandamide are intravenously self-administered by squirrel monkeys. J. Neurosci. 25, 5645-5650.

Kelley, AE., 2004. Ventral striatal control of appetitive motivation: role in ingestive behavior and reward-related learning. Neurosci. Biobehav. Rev. 27, 765-776.

Kelly, T.H., Foltin, R.W., Emurian, C.S., Fischman, M.W., 1994a. Effects of delta 9-THC on marijuana smoking, dose choice, and verbal report of drug liking. J. Exp. Anal. Behav. 61, 203-211.

Kelly, T.H., Foltin, R.W., Mayr, M.T., Fischman, M.W., 1994b. Effects of delta 9tetrahydrocannabinol and social context on marijuana self-administration by humans. Pharmacol. Biochem. Behav. 49, 763-768.

Kelly, T.H., Foltin, R.W., Emurian, C.S., Fischman, M.W., 1997. Are choice and selfadministration of marijuana related to delta 9-THC content? Exp. Clin. Psychopharmacol. 5, 74-82.

Koob, G.F., 1992. Neural mechanisms of drug reinforcement. Ann. N.Y. Acad. Sci. 654, 171-191.

Laszlo, J., Lucas, V.S. Jr., Hanson, D.C., Cronin, C.M., Sallan, S.E. 1981. Levonantradol for chemotherapy-induced emesis: phase I-II oral administration. J. Clin. Pharmacol. 21, 51S-56S.

Laviolette, S.R., Grace, A.A., 2006. The roles of cannabinoid and dopamine receptor systems in neural emotional learning circuits: implications for schizophrenia and addiction. Cell. Mol. Life Sci. 63, 1597-1613.

Ledent, C., Valverde, O., Cossu, G., Petitet, F., Aubert, J.F., Beslot, F., Böhme, G.A., Imperato, A., Pedrazzini, T., Roques, B.P., Vassart, G., Fratta, W., Parmentier, M., 1999. Unresponsiveness to cannabinoids and reduced addictive effects of opiates in CB1 receptor knockout mice. Science 283, 401-404.

Le Foll, B., Goldberg, S.R., 2005. Cannabinoid CB1 receptor antagonists as promising new medications for drug dependence. J. Pharmacol. Exp. Ther. 312, 875-883.

Lepore, M., Liu, X., Savage, V., Matalon, D., Gardner, E.L., 1996. Genetic differences in delta9tetrahydrocannabinol-induced facilitation of brain stimulation reward as measured by a ratefrequency curve-shift electrical brain stimulation paradigm in three different rat strains. Life Sci. 58, PL365-372. 
Lichtman, A.H., Martin, B.R., 2002. Marijuana withdrawal syndrome in the animal model. J. Clin. Pharmacol. 42, 20S-27S.

Lindgren, J.E., Ohlsson, A., Agurell, S., Hollister, L., Gillespie, H., 1981. Clinical effects and plasma levels of delta 9-tetrahydrocannabinol (delta 9-THC) in heavy and light users of cannabis. Psychopharmacology 74, 208-212.

Lupica, C.R., Riegel, A.C., 2005. Endocannabinoid release from midbrain dopamine neurons: a potential substrate for cannabinoid receptor antagonist treatment of addiction. Neuropharmacology 48, 1105-1116.

Mangieri, R.A., Piomelli, D., 2007. Enhancement of endocannabinoid signaling and the pharmacotherapy of depression. Pharmacol. Res. 56, 360-366.

Marinelli, M., Rudick, C.N., Hu, X.T., White, F.J., 2006. Excitability of dopamine neurons: modulation and physiological consequences. CNS Neurol. Disord. Drug Targets 5, 79-97.

Marinelli, S., Di Marzo, V., Florenzano, F., Fezza, F., Viscomi, M.T., van der Stelt, M., Bernardi, G., Molinari, M., Maccarrone, M., Mercuri, N.B., 2007. N-arachidonoyl-dopamine tunes synaptic transmission onto dopaminergic neurons by activating both cannabinoid and vanilloid receptors. Neuropsychopharmacology 32, 298-308.

Marsicano, G., Lutz, B., 1999. Expression of the cannabinoid receptor CB1 in distinct neuronal subpopulations in the adult mouse forebrain. Eur. J. Neurosci. 11, 4213-4225.

Martellotta, M.C., Cossu, G., Fattore, L., Gessa, G.L., Fratta, W., 1998. Self-administration of the cannabinoid receptor agonist WIN 55,212-2 in drug-naive mice. Neuroscience 85, 327-330.

Mascia, M.S., Obinu, M.C., Ledent, C., Parmentier, M., Böhme, G.A., Imperato, A., Fratta, W., 1999. Lack of morphine-induced dopamine release in the nucleus accumbens of cannabinoid CB(1) receptor knockout mice. Eur. J. Pharmacol. 383, R1-R2.

Matsuda, L.A., Bonner, T.I., Lolait, S.J., 1993. Localization of cannabinoid receptor mRNA in rat brain. J. Comp. Neurol. 327, 535-550.

Matthews, R.T., German, D.C., 1984. Electrophysiological evidence for excitation of rat ventral tegmental area dopamine neurons by morphine. Neuroscience 11, 617-625.

McGregor, I.S., Dam, K.D., Mallet, P.E., Gallate, J.E., 2005. Delta9-THC reinstates beer- and sucrose-seeking behaviour in abstinent rats: comparison with midazolam, food deprivation and predator odour. Alcohol Alcohol. 40, 35-45. 
McRae, A.L., Budney, A.J., Brady, K.T., 2003. Treatment of marijuana dependence: a review of the literature. J. Subst. Abuse Treat. 24, 369-376.

Mechoulam, R., Parker, L., 2003. Cannabis and alcohol--a close friendship. Trends Pharmacol. Sci. 24, 266-268.

Melis, M., Perra, S., Muntoni, A.L., Pillola, G., Lutz, B., Marsicano, G., 2004a. Prefrontal cortex stimulation induces 2-arachidonoyl-glycerol-mediated suppression of excitation in dopamine neurons. J. Neurosci. 24, 10707-10715.

Melis, M., Pistis, M., Perra, S., Muntoni, A.L., Pillolla, G., Gessa, G.L., 2004b. Endocannabinoids mediate presynaptic inhibition of glutamatergic transmission in rat ventral tegmental area dopamine neurons through activation of CB1 receptors. J. Neurosci. 24, 53-62.

Melis, M., Pillolla, G., Bisogno, T., Minassi, A., Petrosino, S., Perra S., Muntoni, A.L., Lutz, B., Gessa, G.L., Marsicano, G., Di Marzo, V., Pistis, M., 2006. Protective activation of the endocannabinoid system during ischemia in dopamine neurons. Neurobiol. Dis. 24, 15-27.

Melis, M., Pistis, M., 2007. Endocannabinoid Signaling in Midbrain Dopamine Neurons: More than Physiology? Current Neuropharmacology 5, 268-277.

Mendelson, J.H., Mello, N.K., 1984. Reinforcing properties of oral delta 9-tetrahydrocannabinol, smoked marijuana, and nabilone: influence of previous marijuana use. Psychopharmacology $83,351-356$.

Mendelson, J.H., Mello, N.K., Lex, B.W., Bavli, S., 1984. Marijuana withdrawal syndrome in a woman. Am. J. Psychiatry 141, 1289-1290.

Mereu, G., Yoon, K.W., Boi, V., Gessa, G.L., Naes, L., Westfall, T.C., 1987. Preferential stimulation of ventral tegmental area dopaminergic neurons by nicotine. Eur. J. Pharmacol. 141, 395-399.

Micale, V., Mazzola, C., Drago, F., 2007. Endocannabinoids and neurodegenerative diseases. Pharmacol. Res. 56, 382-392.

Mokler, D.J., Nelson, B.D., Harris, L.S., Rosecrans, J.A., 1986. The role of benzodiazepine receptors in the discriminative stimulus properties of delta-9-tetrahydrocannabinol.Life Sci. 38, 1581-1589.

Moore, B.A., Budney, A.J., 2003. Relapse in outpatient treatment for marijuana dependence. J. Subst. Abuse Treat. 25; 85-89. 
Murray, R.M., Morrison, P.D., Henquet, C., Di Forti, M., 2007. Cannabis, the mind and society: the hash realities. Nat. Rev. Neurosci. 8, 885-895.

Navarro, M., Carrera, M.R., Fratta, W., Valverde, O., Cossu, G., Fattore, L., Chowen, J.A., Gomez, R., del Arco, I., Villanua, M.A., Maldonado, R., Koob, G.F., Rodriguez de Fonseca, F., 2001. Functional interaction between opioid and cannabinoid receptors in drug selfadministration. J. Neurosci. 21, 5344-5350.

Ng Cheong Ton, J.M., Gerhardt, G.A., Friedemann, M., Etgen, A.M., Rose, G.M., Sharpless, N.S., Gardner, E.L., 1988. The effects of delta9-tetrahydrocannabinol on potassium-evoked release of dopamine in the rat caudate nucleus: an in vivo electrochemical and in vivo microdialysis study. Brain Res. 451, 59-68.

Noyes, R. Jr., Brunk, S.F., Baram, D.A., Canter, A., 1975. Analgesic effect of delta-9tetrahydrocannabinol. J. Clin. Pharmacol. 15, 139-143.

Ohlsson, A., Lindgren, .JE., Wahlen, A., Agurell, S., Hollister, L.E., Gillespie, H.K,. 1980. Plasma delta-9 tetrahydrocannabinol concentrations and clinical effects after oral and intravenous administration and smoking. Clin. Pharmacol. Ther. 28, 409-416.

Parrott, A.C., 2006. MDMA in humans: factors which affect the neuropsychobiological profiles of recreational ecstasy users, the integrative role of bioenergetic stress. J. Psychopharmacol. 20, 147-163.

Pettit, H.O., Justice, J.B. Jr., 1989. Dopamine in the nucleus accumbens during cocaine selfadministration as studied by in vivo microdialysis. Pharmacol. Biochem. Behav. 34, 899-904.

Pistis, M., Ferraro, L., Pira, L., Flore, G., Tanganelli, S., Gessa, G.L., Devoto, P., 2002a. Delta(9)-tetrahydrocannabinol decreases extracellular GABA and increases extracellular glutamate and dopamine levels in the rat prefrontal cortex: an in vivo microdialysis study. Brain Res. 948, 155-158.

Pistis, M., Muntoni, A.L., Pillolla, G., Gessa, G.L., 2002b. Cannabinoids inhibit excitatory inputs to neurons in the shell of the nucleus accumbens: an in vivo electrophysiological study. Eur. J. Neurosci. 15, 1795-1802.

Pistis, M., Muntoni, A.L., Pillolla, G., Perra, S., Cignarella, G., Melis, M., Gessa, G.L., 2005. Gamma-hydroxybutyric acid (GHB) and the mesoaccumbens reward circuit: evidence for GABA(B) receptor-mediated effects. Neuroscience 131, 465-474. 
Pontieri, F.E., Tanda, G., Di Chiara, G., 1995. Intravenous cocaine, morphine, and amphetamine preferentially increase extracellular dopamine in the "shell" as compared with the "core" of the rat nucleus accumbens. Proc. Natl. Acad. Sci. U.S.A. 92, 12304-12308.

Racz, I., Bilkei-Gorzo, A., Toth, Z.E., Michel, K., Palkovits, M., Zimmer, A., 2003. A critical role for the cannabinoid CB1 receptors in alcohol dependence and stress-stimulated ethanol drinking. J. Neurosci. 23, 2453-2458.

Raft, D., Gregg, J., Ghia, J., Harris, L., 1977. Effects of intravenous tetrahydrocannabinol on experimental and surgical pain. Psychological correlates of the analgesic response. Clin. Pharmacol. Ther. 21, 26-33.

Riegel, A.C., Lupica, C.R., 2004. Independent presynaptic and postsynaptic mechanisms regulate endocannabinoid signaling at multiple synapses in the ventral tegmental area. J. Neurosci. 24, 11070-11078.

Schultz, W., 1998. Predictive reward signal of dopamine neurons. J. Neurophysiol. 80, 1-27.

Schultz, W., 2002. Getting formal with dopamine and reward. Neuron 36, 241-263.

Schultz, W., 2006. Behavioral theories and the neurophysiology of reward. Annu. Rev. Psychol. $57,87-115$.

Schultz, W., Dickinson, A., 2000. Neuronal coding of prediction errors. Annu. Rev. Neurosci. 23, 473-500.

Serra, G., Fratta, W., 2007. A possible role for the endocannabinoid system in the neurobiology of depression. Clin. Pract. Epidemol. Ment. Health 19, 3:25.

Shoaib, M., 2007. The cannabinoid antagonist AM251 attenuates nicotine self-administration and nicotine-seeking behaviour in rats. Neuropharmacology 54, 438-444.

Solinas, M., Panlilio, L.V., Justinova, Z., Yasar, S., Goldberg, S.R., 2006. Using drugdiscrimination techniques to study the abuse-related effects of psychoactive drugs in rats. Nat. Protoc. 1, 1194-1206.

Solinas, M., Scherma, M., Fattore, L., Stroik, J., Wertheim, C., Tanda, G., Fratta, W., Goldberg, S.R., 2007a. Nicotinic alpha 7 receptors as a new target for treatment of cannabis abuse. J. Neurosci. 27, 5615-5620.

Solinas, M., Yasar, S., Goldberg, SR., 2007b. Endocannabinoid system involvement in brain reward processes related to drug abuse. Pharmacol. Res. 56, 393-405. 
Spano, M.S., Fattore, L., Cossu, G., Deiana, S., Fadda, P., Fratta, W., 2004. CB1 receptor agonist and heroin, but not cocaine, reinstate cannabinoid-seeking behaviour in the rat. Br. J. Pharmacol. 143, 343-350.

Spano, M.S., Ellgren, M., Wang, X., Hurd, Y.L., 2007. Prenatal cannabis exposure increases heroin seeking with allostatic changes in limbic enkephalin systems in adulthood. Biol. Psychiatry 61, 554-563.

Spear, S.F., Ciesla, J.R., Skala, S.Y., 1999. Relapse patterns among adolescents treated for chemical dependency. Subst. Use Misuse 34, 1795-1815.

Stephens, R.S., Roffman, R.A., Simpson, E.E., 1994. Treating adult marijuana dependence: a test of the relapse prevention model. J. Consult. Clin. Psychol. 62, 92-99.

Szabo, B., Siemes, S., Wallmichrath, I., 2002. Inhibition of GABAergic neurotransmission in the ventral tegmental area by cannabinoids. Eur. J. Neurosci. 15, 2057-2061.

Tanda, G., Pontieri, F.E., Di Chiara, G., 1997. Cannabinoid and heroin activation of mesolimbic dopamine transmission by a common mul opioid receptor mechanism. Science 276, 20482050.

Thanos, P.K., Dimitrakakis, E.S., Rice, O., Gifford, A., Volkow, N.D., 2005. Ethanol selfadministration and ethanol conditioned place preference are reduced in mice lacking cannabinoid CB1 receptors. Behav. Brain Res. 164, 206-213.

Trojniar, W., Wise, R.A., 1991. Facilitory effect of delta 9-tetrahydrocannabinol on hypothalamically induced feeding. Psychopharmacology 103, 172-176.

Tzschentke, T.M., 1998. Measuring reward with the conditioned place preference paradigm: a comprehensive review of drug effects, recent progress and new issues. Prog. Neurobiol. 56, 613-672.

Tzschentke, T.M., 2007. Measuring reward with the conditioned place preference (CPP) paradigm: update of the last decade. Addict. Biol. 12, 227-462.

UNODC World Drug Report. United Nations Office on Drugs and Crime (online), 2006. http://www.unodc.org/unodc/en/world_drug_report2006.html (2006)

Van Gaal, L.F., Rissanen, A.M., Scheen, A.J., Ziegler, O., Rössner, S. 2005. Effects of the cannabinoid-1 receptor blocker rimonabant on weight reduction and cardiovascular risk factors in overweight patients: 1-year experience from the RIO-Europe study. Lancet 365, 1389-1397. 
Viveros, M.P., Marco, E.M., File, S.E., 2005. Endocannabinoid system and stress and anxiety responses. Pharmacol. Biochem. Behav. 81, 331-342.

Viveros, M.P., Marco, E.M., File, S.E., 2006. Nicotine and cannabinoids: parallels, contrasts and interactions. Neurosci. Biobehav. Rev. 30, 1161-1181.

Vlachou, S., Nomikos, G.G., Panagis, G., 2005. CB1 cannabinoid receptor agonists increase intracranial self-stimulation thresholds in the rat. Psychopharmacology 179, 498-508.

Vlachou, S., Nomikos, G.G., Stephens, D.N., Panagis, G., 2007. Lack of evidence for appetitive effects of Delta9-tetrahydrocannabinol in the intracranial self-stimulation and conditioned place preference procedures in rodents. Behav. Pharmacol. 18, 311-319.

Voorn, P., Gerfen, C.R., Groenewegen, H.J., 1989. Compartmental organization of the ventral striatum of the rat: immunohistochemical distribution of enkephalin, substance $\mathrm{P}$, dopamine, and calcium-binding protein. J. Comp. Neurol. 289, 189-201.

Wang, G.J., Volkow, N.D., Fowler, J.S., Cervany, P., Hitzemann, R.J., Pappas, N.R., Wong, C.T., Felder, C., 1999. Regional brain metabolic activation during craving elicited by recall of previous drug experiences. Life Sci. 64, 775-784.

Ward, A.S., Comer, S.D., Haney, M., Foltin, R.W., Fischman, M.W., 1997. The effects of a monetary alternative on marijuana self-administration. Behav. Pharmacol. 8, 275-286.

Wenger, T., Moldrich, G., Furst, S., 2003. Neuromorphological background of cannabis addiction. Brain Res. Bull. 61, 125-128.

Wiley, J.L., Huffman, J.W., Balster, R.L., Martin, B.R., 1995. Pharmacological specificity of the discriminative stimulus effects of delta 9-tetrahydrocannabinol in rhesus monkeys. Drug Alcohol Depend. 40, 81-86.

Wiley, J.L., Martin, B.R., 1999. Effects of SR141716A on diazepam substitution for delta9tetrahydrocannabinol in rat drug discrimination. Pharmacol. Biochem. Behav. 64, 519-522.

Wise, R.A., 2004. Dopamine, learning and motivation. Nat. Rev. Neurosci. 5, 483-494.

Xi, Z.X., Gilbert, J.G., Peng, X.Q., Pak, A.C., Li, X., Gardner, E.L., 2006. Cannabinoid CB1 receptor antagonist AM251 inhibits cocaine-primed relapse in rats: role of glutamate in the nucleus accumbens. J. Neurosci. 26, 8531-8536.

Yanovsky, Y., Mades, S., Misgeld, U., 2003. Retrograde signaling changes the venue of postsynaptic inhibition in rat substantia nigra. Neuroscience 122, 317-328. 
Zahm, D.S., Brog, J.S., 1992. On the significance of subterritories in the "accumbens" part of the rat ventral striatum. Neuroscience 50, 751-767. 